\title{
Patellar tendon enthesitis as initial manifestation of ankylosing spondylitis: an atypical presentation
}

\section{Jyoti Panwar Sureka, ${ }^{1}$ Viju Daniel Varghese, ${ }^{2}$ Madhavi Kandagaddala, ${ }^{1}$ Divya Prasanthi ${ }^{1}$}

${ }^{1}$ Department of Radiology, Christian Medical College and Hospital, Vellore, Tamil Nadu, India

${ }^{2}$ Department of Orthopaedics Unit 3, Christian Medical College and Hospital, Vellore, Tamil Nadu, India

\section{Correspondence to} Dr Jyoti Panwar Sureka, drjyoticmch@rediffmail.com

Accepted 15 October 2015
CrossMark

\section{To cite: Sureka JP,} Varghese VD,

Kandagaddala $\mathrm{M}$, et al. BMJ Case Rep Published online: [please include Day Month Year] doi:10.1136/bcr-2015213048

\section{DESCRIPTION}

A 19-year-old man presented to the orthopaedic clinic because of a 3-month history of left anterior

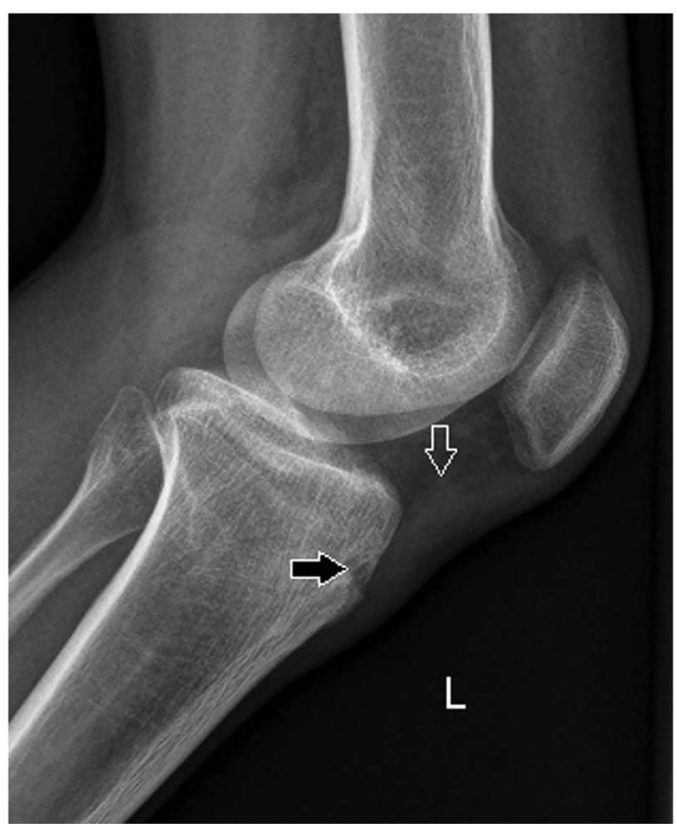

Figure 1 Lateral radiograph of the left knee showing bony prominence and focal lucency (black arrow) at the tibial tubercle and soft tissue thickening of the distal patellar tendon (open arrow). knee pain. There was apparently no history of trauma or other comorbidities. He was not involved in athletic activities. On physical examination, there was tenderness at the tibial tubercle. $\mathrm{He}$ underwent anteroposterior (AP) and lateral radiographs of the left knee, which showed a focal lucency at the tibial tubercle and soft tissue thickening at the distal patellar tendon (figure 1). $\mathrm{He}$

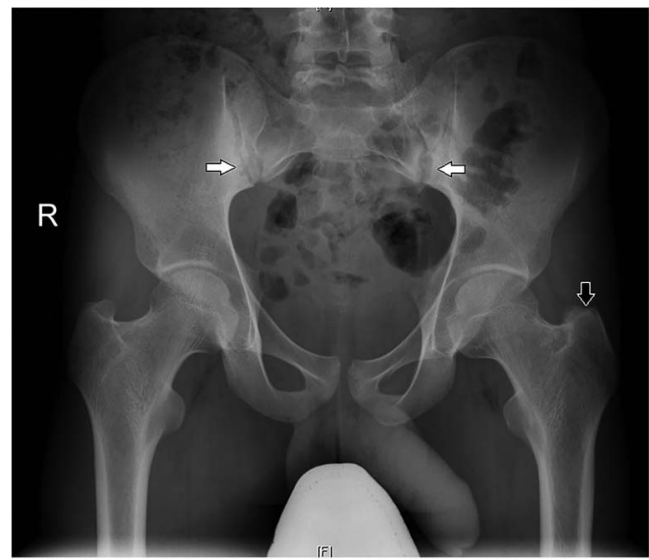

Figure 3 A nteroposteriorradiograph of the pelvis showing irregularity, erosion and subchondral sclerosis (white arrows) of articular surface of lower part of bilateral sacroiliac joints predominantly on iliac side. Note the bony surface irregularity at the left greater trochanter (black arrow) suggesting possible enthesitis.

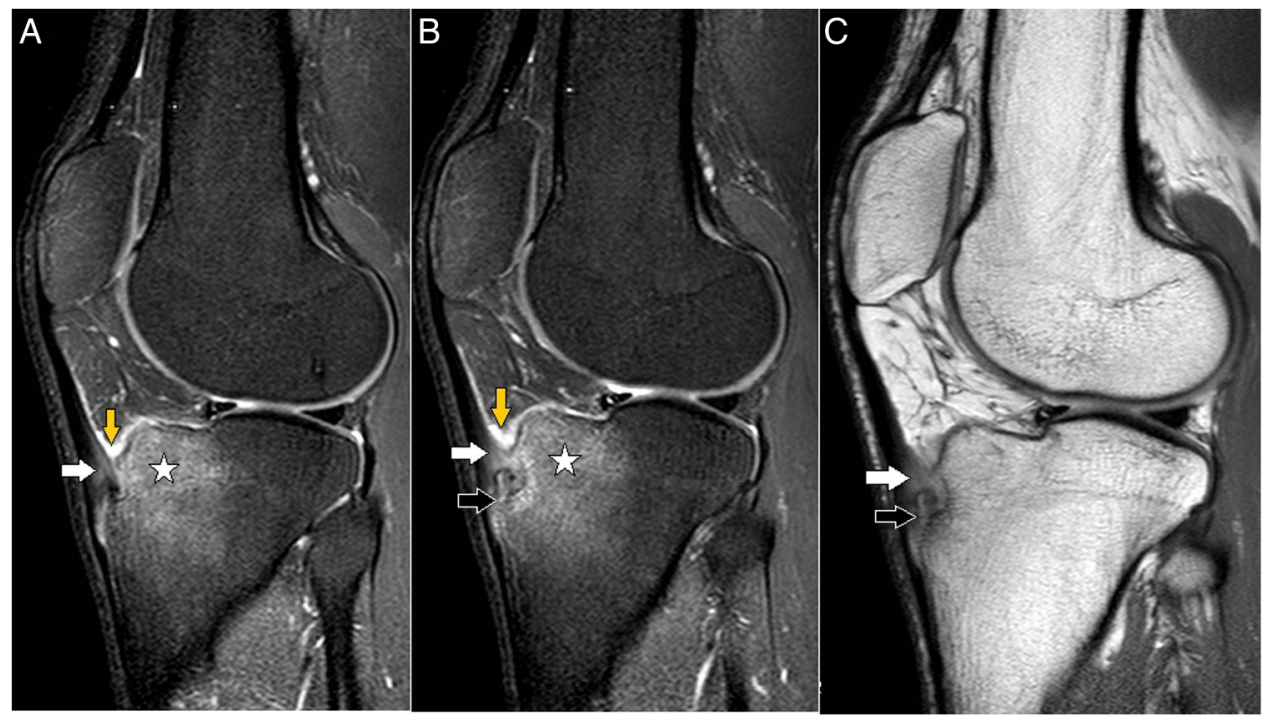

Figure 2 (A and B) T2-weighted fat suppressed and (C) proton density-weighted sagittal images of the left knee showing localised thickening and high signal in the distal patellar tendon (white arrows) at the tibial tubercle attachment, oedema-like marrow signal abnormality in the adjacent tibia (stars), and bony irregularity and small erosions (black arrows) at the tibial tubercle. Note the fluid and inflammatory changes in the deep infrapatellar bursa and adjacent Hoffa's fat pad (yellow arrows). 


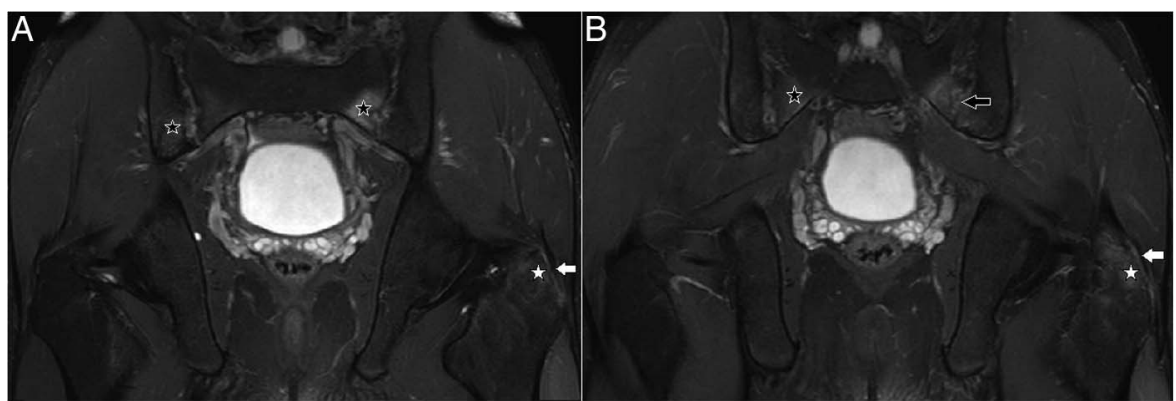

Figure 4 (A and B) T2-weighted fat suppressed coronal images of the pelvis showing oedema-like subchondral marrow signal abnormality (black stars) along both the iliac and sacral side of lower part of bilateral sacroiliac joints with hyperintensity (black arrow) suggesting fluid and/synovitis in the joint space. Note the high signal (white arrows) in the gluteus medius tendon at the greater trochanter (GT) attachment site with associated reactive marrow oedema (white stars) in the adjacent GT confirming enthesitis.

further underwent MRI of the knee and AP radiograph of the pelvis. MRI showed features of Osgood-Schlatter disease (OSD) (figure 2). The pelvic radiograph taken to evaluate referred knee pain revealed bilateral sacroiliitis (figure 3). Subsequent detailed history and clinical examination including a history of low back pain and MRIs of the pelvis confirmed the sacroiliitis (figures 4 and 5).

Thus our case initially mimicked OSD on knee MRI. However, an available plain radiograph of the pelvis, and subsequent MRIs along with clinical examination of sacroiliac joints and positive human leucocyte antigen (HLA) B27 test helped in making the final diagnosis of distal patellar tendon enthesitis accompanying ankylosing spondylitis (AS).

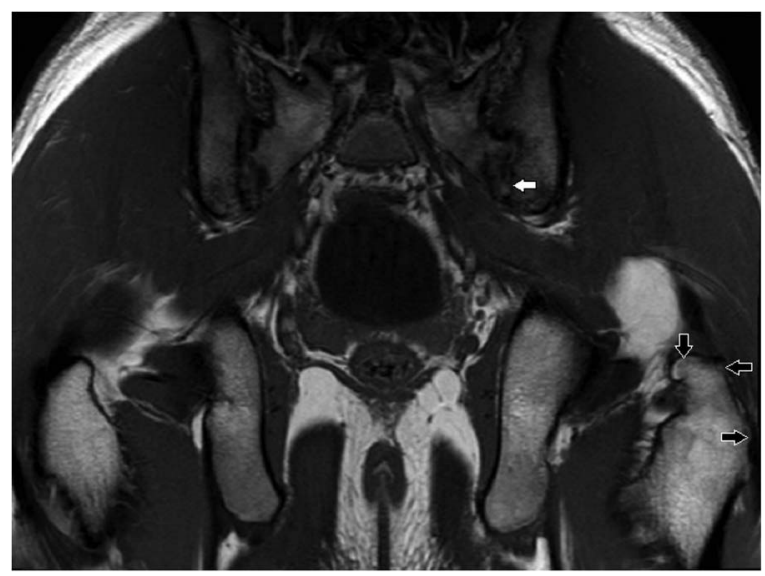

Figure 5 T1-weighted coronal image of the pelvis depicting articular surface irregularity and erosion (white arrow) at the sacroiliac joint and reactive bony proliferation at the greater trochanter (black arrows).
AS is a systemic disorder characterised by inflammatory arthritis and enthesopathy, predominantly affecting the spine and sacroiliac joints. ${ }^{1}$ It may also present with peripheral arthritis and enthesopathy, where inflammation leads to the destruction of attachments of ligaments and tendons to the bone. Resulting erosion leads to reactive new bone formation. ${ }^{1-3}$ The most commonly encountered enthesitis occurs at the sites of insertion of the Achilles tendon and plantar fascia in the heel. ${ }^{2}{ }^{3}$ Involvement of distal patellar tendon insertion at the tibial tubercle is relatively rare and its occurrence as the initial presentation of AS is even rarer.

\section{Learning points}

- The similarity of Osgood-Schlatter disease and enthesitis accompanying ankylosing spondylitis may cause diagnostic difficulty. A high degree of clinical suspicion and further imaging can help in differentiating the two disorders.

- Correct diagnosis will lead to early and appropriate management and better outcome.

Competing interests None declared.

Patient consent Obtained.

Provenance and peer review Not commissioned; externally peer reviewed.

\section{REFERENCES}

1 Appel $H$, Loddenkemper C, Miossec P. Rheumatoid arthritis and ankylosing spondylitis - pathology of acute inflammation. Clin Exp Rheumatol 2009;27:15-19.

2 Eshed I, Bollow M, McGonagle DG, et al. MRI of enthesitis of the appendicular skeleton in spondyloarthritis. Ann Rheum Dis 2007;66:1553-9.

3 Ball J. The enthesopathy of ankylosing spondylitis. Br J Rheumatol 1983;22(4 Suppl 2):25-8. 
Copyright 2015 BMJ Publishing Group. All rights reserved. For permission to reuse any of this content visit http://group.bmj.com/group/rights-licensing/permissions.

BMJ Case Report Fellows may re-use this article for personal use and teaching without any further permission.

Become a Fellow of BMJ Case Reports today and you can:

- Submit as many cases as you like

- Enjoy fast sympathetic peer review and rapid publication of accepted articles

- Access all the published articles

- Re-use any of the published material for personal use and teaching without further permission

For information on Institutional Fellowships contact consortiasales@bmjgroup.com

Visit casereports.bmj.com for more articles like this and to become a Fellow 